\title{
Metastasectomy Improves the Survival of Gastric Cancer Patients with Krukenberg Tumors: A Retrospective Analysis of 182 patients
}

This article was published in the following Dove Press journal: Cancer Management and Research

\author{
Fuhai $\mathrm{Ma}$ (D) \\ Yang Li (D) \\ Weikun Li (iD) \\ Wenzhe Kang (D) \\ Hao Liu (D) \\ Shuai $M a \mathbb{D}^{\prime}$ \\ Yibin Xie (D) \\ Yuxin Zhong $\mathbb{D}^{\prime}$ \\ Quan Xu (D) \\ Bingzhi Wang $\mathbb{D}^{2}$ \\ Liyan Xue $\mathbb{D}^{2}$ \\ Yantao Tian (D) \\ 'Department of Pancreatic and Gastric \\ Surgery, National Cancer Center/ \\ National Clinical Research Center for \\ Cancer/Cancer Hospital, Chinese \\ Academy of Medical Sciences and Peking \\ Union Medical College, Beijing I0002I, \\ People's Republic of China; ${ }^{2}$ Department \\ of Pathology, National Cancer Center/ \\ National Clinical Research Center for \\ Cancer/Cancer Hospital, Chinese \\ Academy of Medical Sciences and Peking \\ Union Medical College, Beijing 10002I, \\ People's Republic of China
}

Correspondence: Yantao Tian Department of Pancreatic and Gastric Surgery, National Cancer Center/ National Clinical Research Center for Cancer/Cancer Hospital, Chinese Academy of Medical Sciences and Peking Union Medical College, Chaoyang District, Beijing 10002I, People's Republic of China

TellFax +86- 10-87787 I 20

Email zlyytyt@I63.com
Purpose: There is no consensus regarding whether metastasectomy in gastric cancer patients with Krukenberg tumors (KTs) is associated with survival benefits. The aim of this study was to evaluate the treatment of KTs of gastric origin in a large series of patients and to identify prognostic factors affecting survival.

Patients and Methods: All patients who were diagnosed with gastric cancer and ovarian metastases in a single medical center between January 2006 and December 2016 were identified and included. The patients were divided into two groups according to treatment modality: a metastasectomy group and a nonmetastasectomy group. Clinicopathological features and overall survival (OS) were compared between the groups.

Results: In total, 182 patients were identified; 94 patients presented with synchronous KTs, and 88 developed metachronous KTs during follow-up. OS was significantly longer in the metastasectomy group than in the nonmetastasectomy group among those with synchronous (14.0 months vs 8.0 months; $\mathrm{p}=0.001$ ) and metachronous (14 months vs 8 months; $\mathrm{p}=0.018$ ) KTs. Multivariate analysis indicated that metastasectomy (hazard ratio [HR] 0.537; 95\% confidence interval [CI] 0.344-0.839; $\mathrm{p}=0.006$ ), ascites (HR 1.523; 95\% CI 1.058-2.193; $\mathrm{p}=0.024)$, linitis plastica (HR 1.995; 95\% CI 1.115-3.571; p = 0.020), and systemic chemotherapy (HR 0.456; $95 \%$ CI $0.280-0.742 ; p=0.002$ ) were independent predictors of OS.

Conclusion: Metastasectomy combined with systemic chemotherapy should be performed in gastric cancer patients with synchronous or metachronous KTs. Metastasectomy, systemic therapy, linitis plastica, and ascites are prognostic factors for OS. Further prospective randomized studies are needed.

Keywords: gastric cancer, ovarian metastasis, Krukenberg tumor, ovarian metastasectomy, survival benefit

\section{Introduction}

Gastric cancer is the fourth most common cancer worldwide and the second leading cause of cancer-related death. ${ }^{1,2}$ Although surgery remains the gold standard therapy for this disease, locoregional relapse or distant metastasis occurs in a majority of patients after curative resection. ${ }^{3}$ Moreover, many patients are diagnosed at advanced stages with synchronous or metachronous metastases in the peritoneum, ovary, and liver. ${ }^{4}$ Despite multimodal therapy and improvement in systemic therapy, the outcomes of these patients remain extremely poor. ${ }^{5}$

A Krukenberg tumor (KT) is a malignancy that has metastasized to the ovaries, and its prognosis is dismal. ${ }^{6,7}$ Gastric cancer is the leading primary origin of $\mathrm{KT},{ }^{8}$ 
and ovarian metastasis is one of the most important causes of treatment failure in gastric cancers among female patients. ${ }^{7,9}$ Unfortunately, no optimal treatment strategies or guidelines for patients diagnosed with KTs of gastric origin have been clearly established. Moreover, only a few studies have assessed the value of metastasectomy for KTs of gastric origin, and the survival benefit of ovarian metastasectomy remains controversial. Indeed, some studies have shown that resection of metastatic tumors can prolong survival, ${ }^{9-12}$ whereas others have found that aggressive surgical therapy offers no benefit. ${ }^{13,14}$

Therefore, we conducted this study to investigate the survival benefit of ovarian metastasectomy for gastric patients with synchronous or metachronous KTs derived from gastric cancer and to identify prognostic factors affecting survival.

\section{Materials and Methods}

All patients who were diagnosed with gastric cancer and ovarian metastases at the Cancer Hospital of the Chinese Academy of Medical Sciences between January 2006 and December 2016 were enrolled in the study. Clinicopathological features and treatment records were reviewed in detail. The diagnosis of KT was based on the pathological evaluation of metastasectomy specimens or computed tomography (CT) or ultrasonography findings. All patients with gastric cancer received a pathological diagnosis. The cancer had been staged according to the American Joint Committee on Cancer (AJCC) tumor node metastasis (TNM) system. All study procedures were approved by the Institutional Review Board of our hospital. The datasets in the current study are available from the corresponding author on reasonable request.

Clinicopathological variables included age $(\geq 45$ or $<45$ years), menopausal status (premenopausal or postmenopausal), primary tumor location, size of the ovarian metastasis, ovarian involvement (unilateral or bilateral), pathology reports, other types of metastasis, extent of the disease, ascites (presence or absence) before or during resection of the ovarian metastasis and systemic chemotherapy. Synchronous KT was defined as the initial presentation of ovarian metastasis; metachronous KT was defined as detection of KTs upon relapse or disease progression after radical gastrectomy. Ascites was determined by CT or ultrasonography before ovarian metastasectomy or was found during the operation. At the completion of metastasectomy, the residual disease state of each patient was recorded according to the presence or absence of gross residual disease, which was classified as negative resection margins (R0), microscopic tumor infiltration (R1), and macroscopic residual tumor (R2).

Chemotherapy was administered in all synchronous KT patients who did not undergo metastasectomy and 14 metachronous KT patients who did not undergo metastasectomy (82.4\%). 49 synchronous KT patients and 48 metachronous KT patients who underwent metastasectomy received chemotherapy, while 8 patients with synchronous KT and 23 patients with metachronous KT who underwent metastasectomy did not receive chemotherapy due to poor performance status after metastasectomy or toxicity concerns. The majority of the patients received 2- or 3-drug combinations, usually for 4-8 cycles. The main chemotherapeutic drugs included cisplatin, carboplatin, oxaliplatin, taxane, irinotecan and 5-fluorouracil.

To compare overall survival (OS), patients were divided into two groups according to the treatment modality they received: a metastasectomy group and a nonmetastasectomy group. For patients with synchronous KTs, OS was defined as the time from the date of the pathologic diagnosis of gastric cancer to the date of death or last follow-up. For patients with metachronous KTs, OS was defined as the time from the date of KT diagnosis by imaging to the date of death or the last follow-up. Evaluation of patient survival was performed by follow-up contact via telephone calls and using outpatient records. Patients were followed up until death or December 31, 2018.

\section{Statistical Analyses}

A chi-square test or Fisher's exact test was applied to compare clinicopathologic data. Comparisons of continuous variables were performed using the $t$ test. Cumulative survival rates were obtained using the Kaplan-Meier method and compared using the log rank test to evaluate statistically significant differences. Cox proportional hazards regression analysis was employed to evaluate factors affecting OS. A p value $<0.05$ was considered significant. The statistical analysis was performed with SPSS for Windows version 22.0.

\section{Results}

\section{Patient Clinicopathological Characteristics}

A total of 94 patients with synchronous KTs were included in this study; $57(60.6 \%)$ and 37 (39.4\%) patients did and did not undergo metastasectomy for KTs, respectively. The clinical characteristics of the synchronous KT patients are 
Table I Clinical Characteristics of 94 Patients with Synchronous Krukenberg Tumors

\begin{tabular}{|c|c|c|c|}
\hline Variable & Metastasectomy n=57 (\%) & Nonmetastasectomy $n=37$ (\%) & p value \\
\hline $\begin{array}{l}\text { Age } \\
\qquad \begin{array}{l}\geq 45 \\
<45\end{array}\end{array}$ & $\begin{array}{l}17(29.8) \\
40(70.2)\end{array}$ & $\begin{array}{l}13(35.1) \\
24(64.9)\end{array}$ & 0.598 \\
\hline $\begin{array}{l}\text { Year of diagnosis } \\
2006-2008 \\
2009-2012 \\
2013-2016\end{array}$ & $\begin{array}{l}14(24.6) \\
22(38.6) \\
21(36.8)\end{array}$ & $\begin{array}{l}5(13.5) \\
20(54.1) \\
12(32.4)\end{array}$ & 0.262 \\
\hline $\begin{array}{l}\text { Menstrual status } \\
\text { Premenopausal } \\
\text { Postmenopausal }\end{array}$ & $\begin{array}{l}39(68.4) \\
18(31.6)\end{array}$ & $\begin{array}{l}31(83.8) \\
6(16.2)\end{array}$ & 0.095 \\
\hline $\begin{array}{l}\text { Tumor location } \\
\text { Upper I/3 } \\
\text { Middle I/3 } \\
\text { Lower I/3 } \\
\text { Whole stomach }\end{array}$ & $\begin{array}{l}6(10.5) \\
19(33.3) \\
22(38.6) \\
10(17.5)\end{array}$ & $\begin{array}{l}4(10.8) \\
12(32.4) \\
14(37.8) \\
7(18.9)\end{array}$ & 1.000 \\
\hline $\begin{array}{l}\text { Linitis plastica } \\
\text { Yes } \\
\text { No }\end{array}$ & $\begin{array}{l}6(10.5) \\
51(89.5)\end{array}$ & $\begin{array}{l}4(10.8) \\
33(89.2)\end{array}$ & 1.000 \\
\hline $\begin{array}{l}\text { Signet-ring cells } \\
\text { Yes } \\
\text { No }\end{array}$ & $\begin{array}{l}31(54.4) \\
26(45.6)\end{array}$ & $\begin{array}{l}19(51.4) \\
18(48.6)\end{array}$ & 0.773 \\
\hline $\begin{array}{l}\text { Laterality } \\
\text { Bilateral } \\
\text { Unilateral }\end{array}$ & $\begin{array}{l}48(84.2) \\
9(15.8)\end{array}$ & $\begin{array}{l}27(73.0) \\
10(27.0)\end{array}$ & 0.185 \\
\hline Tumor size $(\mathrm{cm})$ & $8.7 \pm 4.5$ & $6.2 \pm 3.0$ & 0.031 \\
\hline $\begin{array}{l}\text { Pathologic differentiation } \\
\text { Differentiated } \\
\text { Undifferentiated }\end{array}$ & $\begin{array}{l}8(14.0) \\
49(86.0)\end{array}$ & $\begin{array}{l}5(13.5) \\
32(86.5)\end{array}$ & 0.943 \\
\hline $\begin{array}{l}\text { Other types of metastasis } \\
\text { Peritoneum } \\
\text { Liver } \\
\text { Supraclavicular lymph nodes } \\
\text { Bone } \\
\text { Lung } \\
\text { Other }\end{array}$ & $\begin{array}{l}37(64.9) \\
37(64.9) \\
0 \\
0 \\
1 \\
2 \\
0\end{array}$ & $\begin{array}{l}31(83.8) \\
28(75.7) \\
3 \\
6 \\
2 \\
2 \\
2\end{array}$ & $\begin{array}{l}0.046 \\
0.270\end{array}$ \\
\hline $\begin{array}{l}\text { Ascites } \\
\text { Yes } \\
\text { No }\end{array}$ & $\begin{array}{l}30(52.6) \\
27(47.4)\end{array}$ & $\begin{array}{l}26(70.3) \\
\text { II (29.7) }\end{array}$ & 0.089 \\
\hline $\begin{array}{l}\text { Gastrectomy } \\
\text { Yes } \\
\text { No } \\
\text { Distal gastrectomy } \\
\text { Proximal gastrectomy } \\
\text { Total gastrectomy }\end{array}$ & $\begin{array}{l}28(49.1) \\
29(50.9) \\
17 \\
3 \\
8\end{array}$ & $\begin{array}{l}0(0) \\
37(100) \\
- \\
- \\
-\end{array}$ & $<0.001$ \\
\hline $\begin{array}{l}\text { Systemic chemotherapy } \\
\text { Yes } \\
\text { No }\end{array}$ & $\begin{array}{l}49(86.0) \\
8(14.0)\end{array}$ & $\begin{array}{l}37(100) \\
0(0)\end{array}$ & 0.020 \\
\hline
\end{tabular}


listed in Table 1. Patients who underwent metastasectomy had significantly larger KTs $(8.7 \pm 4.5$ vs $6.2 \pm 3.0 \mathrm{~cm}$, $\mathrm{p}=0.031)$ and fewer metastases outside the ovaries $(64.9 \%$ vs $83.8 \%, p=0.046)$ and were less likely to receive systemic chemotherapy $(86.0 \%$ vs $100 \%, p=0.02)$ than those who did not undergo metastasectomy. In both groups, there were more premenopausal patients than postmenopausal patients and more patients aged $<45$ years. Year of diagnosis, KT laterality, tumor location, histological type and proportion of linitis plastica and presence of ascites were not significantly different between the two groups.

The clinicopathological features of the patients with metachronous KTs are summarized in Table 2. A total of $71(80.7 \%)$ patients received metastasectomy, whereas 17 (19.3\%) patients did not. The clinical characteristics of both groups were similar.

\section{Treatment Outcome and Prognostic Factors}

The median OS for all patients with synchronous KTs was 12.0 months (95\% confidence interval [CI], 9.727 to 14.237 months). The median OS was significantly longer for the metastasectomy group (14.0 months, 95\% CI, 12.109 to 15.891 months) than for the nonmetastasectomy group (8.0 months, 95\% CI, 6.939 to 9.061 months) ( $\mathrm{p}=$ 0.001 , Figure 1). For patients with metachronous KTs, the median OS was 13.0 months (95\% CI 7.958 to 18.042). Additionally, the median survival time in the metastasectomy group was 14.0 months (95\% CI, 8.524 to 19.476 months), compared with 8.0 months (95\% CI, 4.966 to 11.034 months) in the nonmetastasectomy group ( $\mathrm{p}=$ 0.018 , Figure 2). As shown in Figure 3, the R0 resection group $(n=60)$ had a significantly longer OS $(\mathrm{p}<0.001)$ than the $R 1, R 2$ resection group $(n=68)$. The median OS was 19.0 months (95\% CI, 12.194 to 25.806$)$ in the R0 resection group and 10.0 months $(95 \% \mathrm{CI}, 7.182$ to 12.818 ) in the $\mathrm{R} 1, \mathrm{R} 2$ resection group.

Univariate and multivariate analyses of predictors for KT patients are presented in Table 3. In the univariate analysis, metastasectomy, gastrectomy, synchronous disease, peritoneal carcinomatosis, other types of metastasis, linitis plastica and ascites were found to be prognostic factors associated with OS. In the multivariate analysis, metastasectomy (hazard ratio [HR] 0.537; 95\% CI 0.344$0.839 ; \mathrm{p}=0.006)$ and systemic chemotherapy (HR 0.456 ; $95 \%$ CI $0.280-0.742 ; \mathrm{p}=0.002$ ) were independently and strongly associated with a better OS. In contrast, the presence of ascites (HR 1.523; 95\% CI 1.058-2.193; p = 0.024 ) and linitis plastica (HR 1.995; 95\% CI 1.115$3.571 ; \mathrm{p}=0.020$ ) was associated with reduced OS.

\section{Discussion}

Our study demonstrates that metastasectomy significantly increases the survival of patients with KTs originating from gastric cancer. OS was significantly longer in the metastasectomy group than in the nonmetastasectomy group among patients with synchronous KTs (14.0 months vs 8.0 months; $\mathrm{p}=0.001$ ) as well as those with metachronous KTs (14.0 months vs 8.0 months; $\mathrm{p}=0.018)$. Metastasectomy, ascites, linitis plastica and systemic therapy were found to be independent predictors of OS.

$\mathrm{KT}$ occurs in $0.3-6.7 \%$ of patients who undergo surgery for gastric cancer, although the incidence based on autopsies of gastric cancer patients is much higher $(33-41 \%) .{ }^{15,16}$ Previous studies have shown that the prognosis of patients with KT is very poor, with a median survival ranging from 9 to 11 months. ${ }^{8}$ In fact, the prognosis of patients with gastric cancer with metastasis to the ovaries has been reported to be worse than that of patients with other primary tumors. ${ }^{17}$ Despite many efforts to address this issue, there are very few reports regarding the surgical treatment of ovarian metastasis of gastric cancer because of its relatively low incidence. Accordingly, the survival benefit of surgical metastasectomy remains controversial. For example, Cho et al reported that OS was significantly increased in the metastasectomy group relative to the nonmetastasectomy group among patients with synchronous (18.0 months vs 8.0 months; $\mathrm{p}<0.001)$ and metachronous (19.0 months vs 9.0 months; $\mathrm{p}=0.002$ ) KTs derived from gastric cancer. ${ }^{9}$ Additionally, Lu et al found that patients who underwent metastasectomy had a better OS than patients who did not undergo metastasectomy (14.1 months vs 8.0 months, $\mathrm{p}=0.001) .{ }^{10}$ In contrast, some studies have reported that metastasectomy significantly improves OS among patients with ovarian metastasis from colorectal cancer but not among those with metastasis from gastric cancer. ${ }^{17}$ Based on our results, metastasectomy should be performed in patients diagnosed with synchronous or metachronous KTs from gastric cancer, and our recommendation is consistent with that of previous studies.

Although the presence of ascites and linitis plastica have not been well established as prognostic factors for KT, they were found to be predictive factors for poor prognosis in our 
Table 2 Clinical Characteristics of 88 Patients with Metachronous Krukenberg Tumors

\begin{tabular}{|c|c|c|c|}
\hline Variable & Metastasectomy n=7 I (\%) & Nonmetastasectomy $n=17$ (\%) & p value \\
\hline Age & & & 0.618 \\
\hline$\geq 45$ & 34 (47.9) & $7(4 \mid .2)$ & \\
\hline$<45$ & $37(52.1)$ & $10(58.8)$ & \\
\hline Year of diagnosis & & & 0.552 \\
\hline 2006-2008 & $21(29.6)$ & $3(17.6)$ & \\
\hline $2009-2012$ & $26(36.6)$ & $6(35.3)$ & \\
\hline $2013-2016$ & $24(33.8)$ & $8(47.1)$ & \\
\hline Menstrual status & & & 0.507 \\
\hline Premenopausal & $44(62.0)$ & $12(70.6)$ & \\
\hline Postmenopausal & $27(38.0)$ & $5(29.4)$ & \\
\hline Tumor location & & & 0.394 \\
\hline Upper I/3 & $12(16.9)$ & I (5.9) & \\
\hline Middle I/3 & $12(16.9)$ & I (5.9) & \\
\hline Lower I/3 & $42(59.2)$ & 14 (82.3) & \\
\hline Whole stomach & $5(7.0)$ & I (5.9) & \\
\hline Linitis plastica & & & 0.616 \\
\hline Yes & $5(7.0)$ & $2(I I .8)$ & \\
\hline No & $66(93.0)$ & $15(88.2)$ & \\
\hline Signet-ring cells & & & 0.493 \\
\hline Yes & $23(32.4)$ & $7(4 \mid .2)$ & \\
\hline No & $48(67.6)$ & $10(58.8)$ & \\
\hline Laterality & & & 1.000 \\
\hline Bilateral & $53(74.6)$ & $13(76.5)$ & \\
\hline Unilateral & $18(25.4)$ & $4(23.5)$ & \\
\hline Tumor size & $8.9 \pm 4.8$ & $7.3 \pm 4.2$ & 0.322 \\
\hline Pathologic differentiation & & & 0.066 \\
\hline Differentiated & $5(7.0)$ & $4(23.5)$ & \\
\hline Undifferentiated & $66(93.0)$ & $13(76.5)$ & \\
\hline Other types of metastasis & $33(46.5)$ & II (64.7) & 0.233 \\
\hline Peritoneum & $33(46.5)$ & $6(35.3)$ & 0.404 \\
\hline Liver & 1 & 1 & \\
\hline Supraclavicular lymph node & 0 & 1 & \\
\hline Bone & 2 & 0 & \\
\hline Lung & I & 0 & \\
\hline Other & 1 & 4 & \\
\hline Ascites & & & 0.951 \\
\hline Yes & $34(47.9)$ & $8(47.1)$ & \\
\hline No & $37(52.1)$ & $9(52.9)$ & \\
\hline Procedure of gastrectomy & & & 0.357 \\
\hline Distal gastrectomy & $49(69.0)$ & $9(53.0)$ & \\
\hline Proximal gastrectomy & $5(7.0)$ & I (5.9) & \\
\hline Total gastrectomy & $17(24.0)$ & $7(4 I . I)$ & \\
\hline Systemic chemotherapy & & & 0.231 \\
\hline Yes & $48(67.6)$ & $14(82.4)$ & \\
\hline No & $23(32.4)$ & $3(17.6)$ & \\
\hline
\end{tabular}




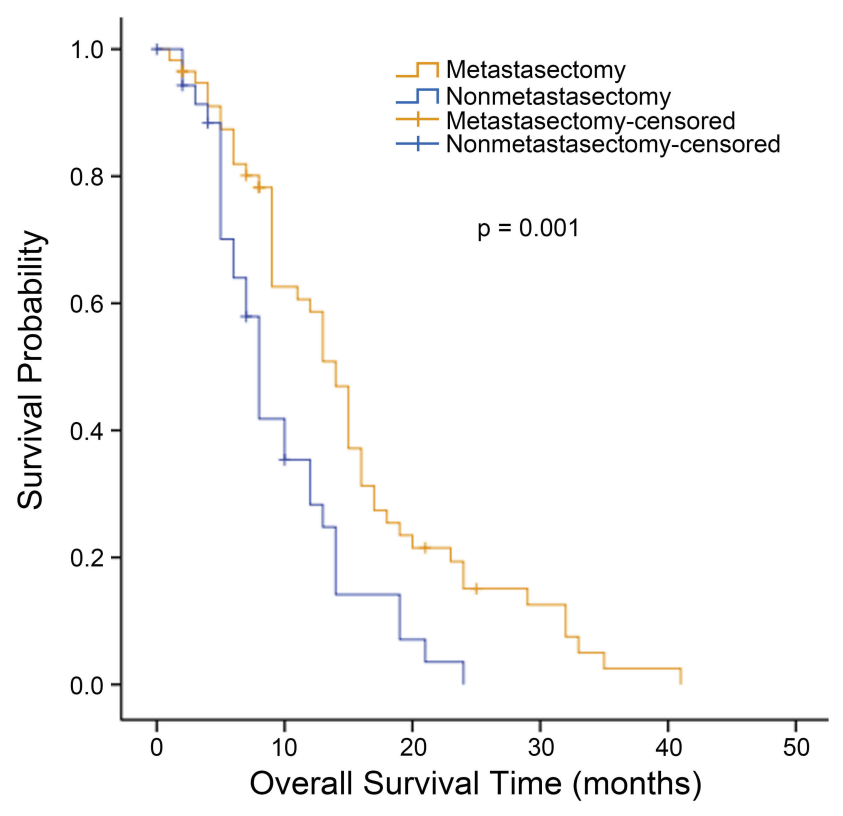

Figure I Kaplan-Meier analysis of overall survival in patients with synchronous Krukenberg tumors who did or did not undergo metastasectomy.

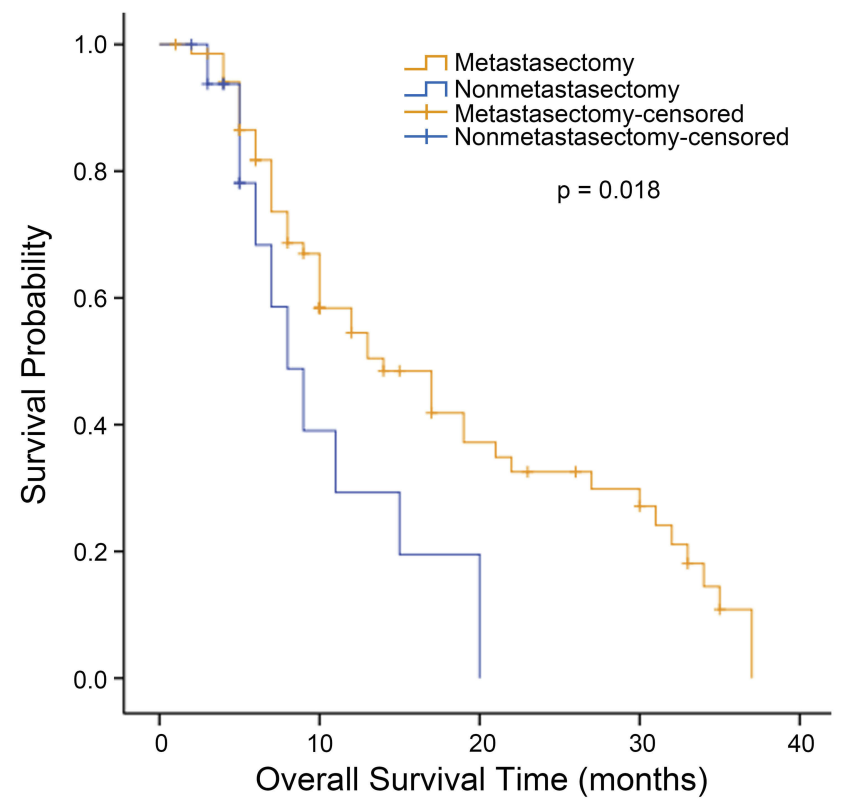

Figure 2 Kaplan-Meier analysis of overall survival in patients with metachronous Krukenberg tumors who did or did not undergo metastasectomy.

study. According to Peng et al, the OS of patients with ascites who receive metastasectomy is similar to that of patients with metastatic gastric cancer who are treated by chemotherapy. ${ }^{18}$ Nonetheless, several reports have suggested that the presence of ascites is associated with poor OS in advanced gastric cancer. ${ }^{19,20}$ Ascites in gastric cancer patients may be caused by tumor invasion of the peritoneum or by malnutrition. ${ }^{18} \mathrm{In}$

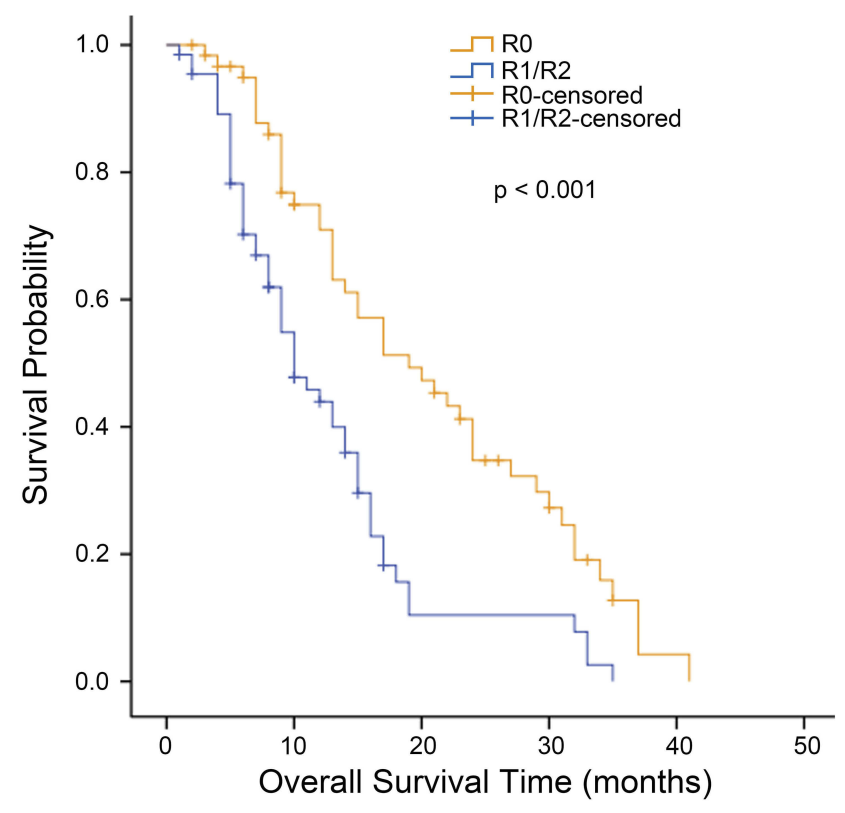

Figure 3 Kaplan-Meier analysis of overall survival in patients who underwent metastasectomy according to the residual disease state. The residual disease state of each patient was documented as the presence or absence of gross residual disease, which was classified as negative resection margins (R0), microscopic tumor infiltration (RI), and macroscopic residual tumor (R2).

general, the presence of ascites is one of the most common complications of advanced gastric cancer, resulting in several symptoms as well as critical complications, such as bowel obstruction, bile duct obstruction, and hydronephrosis. ${ }^{21}$ Therefore, KT metastasectomy should be recommended in patients who do not present ascites. Linitis plastica is a gastric cancer of a diffuse histotype that is characterized by a thickening of the stomach wall and deformation of the stomach, resulting in a leather bottle-like appearance. ${ }^{22}$ Many studies have demonstrated that the presence of linitis plastica is independently associated with poor outcomes, ${ }^{23}$ and our study confirms that linitis plastica is independently associated with a poor prognosis.

Studies evaluating the role of chemotherapy in the treatment of KT are scarce, and the role of chemotherapy remains controversial. Lu et al reported a relatively better OS resulting from systemic therapy with platinum-based chemotherapy after KT metastasectomy. ${ }^{10}$ In a study by Cho et al, the response rates to chemotherapy regimens among 111 patients with KTs ranged from $12 \%$ to $26 \%$, indicating lower levels of chemotherapy responsiveness than for other sites of metastasis. ${ }^{9}$ In our study, the majority of the patients were able to undergo systemic chemotherapy, and survival benefits were observed. 
Table 3 Univariate and Multivariate Analyses of Overall Survival in 182 Patients

\begin{tabular}{|c|c|c|c|c|}
\hline \multirow[t]{2}{*}{ Variable } & \multicolumn{2}{|l|}{ Univariate } & \multicolumn{2}{|l|}{ Multivariate } \\
\hline & Hazard Ratio & p value & Hazard Ratio & p value \\
\hline Age $(>45)$ & $0.87 \mid(0.618-1.227)$ & 0.428 & - & - \\
\hline Menstrual status & I.07। (0.748-I.534) & 0.708 & - & - \\
\hline Size of Krukenberg tumor $(>10 \mathrm{~cm})$ & $0.726(0.493-1.068)$ & 0.104 & - & - \\
\hline Bilateral ovarian metastases & $1.064(0.707-1.601)$ & 0.765 & - & - \\
\hline Gastrectomy & $0.568(0.403-0.801)$ & 0.001 & $0.695(0.39 \mid-1.233)$ & 0.213 \\
\hline Metastasectomy & $0.466(0.319-0.68 I)$ & 0.000 & $0.537(0.344-0.839)$ & 0.006 \\
\hline Synchronous disease & $1.402(0.997-1.97 I)$ & 0.052 & $1.030(0.604-1.758)$ & 0.913 \\
\hline Linitis plastica & $1.839(1.049-3.222)$ & 0.033 & $1.995(1.115-3.571)$ & 0.020 \\
\hline Ascites & $1.778(1.262-2.506)$ & 0.001 & $1.523(1.058-2.193)$ & 0.024 \\
\hline Peritoneal carcinomatosis & $1.423(1.011-2.003)$ & 0.043 & $1.012(0.703-1.481)$ & 0.914 \\
\hline Other types of metastasis & $1.785(1.078-2.956)$ & 0.024 & $1.289(0.744-2.233)$ & 0.365 \\
\hline Systemic chemotherapy & $0.64 \mid(0.4 \mid 2-0.996)$ & 0.048 & $0.456(0.28 I-0.742)$ & 0.002 \\
\hline
\end{tabular}

We defined OS as the interval from the date of diagnosis of ovarian metastasis to the last follow-up date or death. In fact, the difference in OS may have been underestimated because in the metachronous group, OS was determined from the date of KT diagnosis and not from the date of gastric cancer diagnosis.

This study has several limitations. First, its retrospective nature may have introduced selection bias, and no data on the cause of death were available. Second, all patients analyzed were from a single institution; therefore, the results may not be generalizable to other settings. Furthermore, no data regarding quality of life after surgery were available.

\section{Conclusion}

In conclusion, based on our results, metastasectomy combined with systemic therapy should be performed for gastric cancer patients with synchronous or metachronous KTs. Furthermore, we found metastasectomy, systemic therapy, linitis plastica, and ascites to be prognostic factors for OS in KT patients. Consequently, a prospective study on the usefulness of metastasectomy is definitely warranted.

\section{Abbreviations}

KT, Krukenberg tumor; OS, Overall survival; CI, Confidence interval; HR, Hazard ratio.

\section{Ethics Approval and Informed Consent}

This study was approved by the Institutional Review Board at the Cancer Hospital of the Chinese Academy of
Medical Sciences. Consent to participate was not applicable due to the retrospective nature of the study, and the data were anonymously analyzed.

\section{Availability of Data and Material}

The datasets in the current study are available from the corresponding author on request.

\section{Acknowledgments}

The abstract of this paper was presented as an oral presentation at the Korea International Gastric Cancer Week 2019 and as a poster presentation at the International Gastric Cancer Congress 2019.

\section{Author Contributions}

All authors contributed to data analysis, drafting or revising the article, gave final approval of the version to be published, and agree to be accountable for all aspects of the work.

\section{Funding}

This work was supported by the National Natural Science Foundation of China (grant number, 81772642), the Beijing Municipal Science \& Technology Commission (grant number, Z161100000116045), and Capital's Funds for Health Improvement and Research (grant number, CFH 2018-2-4022).

\section{Disclosure}

The authors declare that they have no conflicts of interest in this work. 


\section{References}

1. Jemal A, Bray F, Center MM, Ferlay J, Ward E, Forman D. Global cancer statistics. CA Cancer J Clin. 2011;61(2):69-90. doi:10.3322/ caac.v61:2

2. Van Cutsem E, Sagaert X, Topal B, Haustermans K, Prenen H. Gastric cancer. Lancet. 2016;388(10060):2654-2664. doi:10.1016/ S0140-6736(16)30354-3

3. Kim NK, Kim HK, Park BJ, et al. Risk factors for ovarian metastasis following curative resection of gastric adenocarcinoma. Cancer-Am Cancer Soc. 1999;85(7):1490-1499.

4. Wu XJ, Yuan P, Li ZY, et al. Cytoreductive surgery and hyperthermic intraperitoneal chemotherapy improves the survival of gastric cancer patients with ovarian metastasis and peritoneal dissemination. Tumour Biol. 2013;34(1):463-469. doi:10.1007/s13277-012-0571-4

5. Kim KH, Lee KW, Baek SK, et al. Survival benefit of gastrectomy \pm metastasectomy in patients with metastatic gastric cancer receiving chemotherapy. Gastric Cancer. 2011;14(2):130-138. doi:10.1007/ s10120-011-0015-7

6. Baba Y, Ishikawa S, Ikeda K, et al. A patient with 43 synchronous early gastric carcinomas with a Krukenberg tumor and pericardial metastasis. Gastric Cancer. 2007;10(2):135-139. doi:10.1007/ s10120-007-0416-9

7. Rosa F, Marrelli D, Morgagni P, et al. Krukenberg tumors of gastric origin: the rationale of surgical resection and perioperative treatments in a multicenter western experience. World $J$ Surg. 2016;40 (4):921-928. doi:10.1007/s00268-015-3326-8

8. Kiyokawa T, Young RH, Scully RE. Krukenberg tumors of the ovary: a clinicopathologic analysis of 120 cases with emphasis on their variable pathologic manifestations. Am J Surg Pathol. 2006;30 (3):277-299. doi:10.1097/01.pas.0000190787.85024.cb

9. Cho JH, Lim JY, Choi AR, et al. Comparison of surgery plus chemotherapy and palliative chemotherapy alone for advanced gastric cancer with Krukenberg tumor. Cancer Res Treat. 2015;47 (4):697-705. doi:10.4143/crt.2013.175

10. Lu LC, Shao YY, Hsu CH, et al. Metastasectomy of Krukenberg tumors may be associated with survival benefits in patients with metastatic gastric cancer. Anticancer Res. 2012;32(8):3397-3401.

11. Cheong JH, Hyung WJ, Chen J, Kim J, Choi SH, Noh SH. Survival benefit of metastasectomy for Krukenberg tumors from gastric cancer. Gynecol Oncol. 2004;94(2):477-482. doi:10.1016/j.ygyno. 2004.05.007
12. Yu P, Huang L, Cheng G, et al. Treatment strategy and prognostic factors for Krukenberg tumors of gastric origin: report of a 10-year single-center experience from China. Oncotarget. 2017;8 (47):82558-82570. doi:10.18632/oncotarget.19759

13. Mrad K, Morice P, Fabre A, et al. Krukenberg tumor: a clinico-pathological study of 15 cases. Ann Pathol. 2000;20(3):20 2-206.

14. Savey L, Lasser P, Castaigne D, Michel G, Bognel C, Colau JC. [Krukenberg tumors. Analysis of a series of 28 cases]. J Chir (Paris). 1996;133(9-10):427-431.

15. Wang J, Shi YK, Wu LY, et al. Prognostic factors for ovarian metastases from primary gastric cancer. Int $J$ Gynecol Cancer. 2008;18(4):825-832. doi:10.1111/j.1525-1438.2007.01078.x

16. Kim HK, Heo DS, Bang YJ, Kim NK. Prognostic factors of Krukenberg's tumor. Gynecol Oncol. 2001;82(1):105-109. doi:10. 1006/gyno.2001.6210

17. Jiang R, Tang J, Cheng X, Zang RY. Surgical treatment for patients with different origins of Krukenberg tumors: outcomes and prognostic factors. Eur J Surg Oncol. 2009;35(1):92-97. doi:10.1016/j. ejso.2008.05.006

18. Peng W, Hua RX, Jiang R, et al. Surgical treatment for patients with Krukenberg tumor of stomach origin: clinical outcome and prognostic factors analysis. PLoS ONE. 2013;8(7):e68227. doi:10.1371/journal.pone. 0068227

19. Matsumoto H, Kawazoe A, Shimada K, et al. A retrospective study of the safety and efficacy of paclitaxel plus ramucirumab in patients with advanced or recurrent gastric cancer with ascites. BMC Cancer. 2018;18(1):120. doi:10.1186/s12885-018-4057-7

20. Benizri EI, Bereder JM, Rahili A, Bernard JL, Benchimol D. Ascites and malnutrition are predictive factors for incomplete cytoreductive surgery for peritoneal carcinomatosis from gastric cancer. Am J Surg. 2013;205(6):668-673. doi:10.1016/j.amjsurg.2012.06.009

21. Maeda H, Kobayashi M, Sakamoto J. Evaluation and treatment of malignant ascites secondary to gastric cancer. World J Gastroenterol. 2015;21(39):10936-10947. doi:10.3748/wjg.v21.i39.10936

22. Tseveldorj N, Koklu S, Katipoglu K. An unusual cause of gastric linitis plastica. Gastroenterology. 2016;151(6):e10-e11. doi:10.1053/ j.gastro.2016.07.019

23. Luu C, Thapa R, Woo K, et al. Does histology really influence gastric cancer prognosis? J Gastrointest Oncol. 2017;8(6):1026-1036. doi: $10.21037 /$ jgo

\section{Publish your work in this journal}

Cancer Management and Research is an international, peer-reviewed open access journal focusing on cancer research and the optimal use of preventative and integrated treatment interventions to achieve improved outcomes, enhanced survival and quality of life for the cancer patient.
The manuscript management system is completely online and includes a very quick and fair peer-review system, which is all easy to use. Visit http://www.dovepress.com/testimonials.php to read real quotes from published authors. 